\title{
APLIKASI PEWARNAAN TITIK PADA GRAPH DALAM PEMBUATAN JADWAL PELAJARAN
}

\author{
Safiil Maarif \\ Program Studi Pendidikan Matematika STKIP PGRI Jombang \\ safiil_m@yahoo.com
}

\begin{abstract}
Abstrak: Membuat jadwal pelajaran merupakan salah satu tugas yang harus dikerjakan oleh wakil kepala sekolah bidang kurikulum setiap awal tahun pelajaran. Pembuatan jadwal akan menjadi masalah ketika jadwal yang disusun tidak dapat diselesaikan sebelum kegiatan efektif sekolah. Selama jadwal pelajaran belum selesai disusun maka kegiatan belajar mengajar di sekolah kurang efektif. Jadwal yang dibuat pada awal tahun pelajaran harus bersifat efektif agar tidak terjadi perubahan-perubahan jadwal yang memiliki banyak kendala seperti menyesuaikan hari dengan permintaan guru dan lain sebagainya. Untuk mengatasi permasalahan dalam pembuatan jadwal, salah satu solusi yang bisa digunakan yaitu menggunakan pewarnaan titik pada graph. Tujuan dari penelitian adalah untuk mendeskripsikan aplikasi pewarnaan titik pada graph dalam membuat jadwal pelajaran di MTs Al-Hikmah Janti Jogoroto Jombang. Jenis penelitin ini adalah penelitian kualitatif. Intrumen penelitian ini adalah peneliti sendiri sebagai instrumen utama dan pedoman dokumentasi sebagai instrumet pendukung. Analisis data yang peneliti gunakan adalah Membuat simbol warna untuk masing-masing mata pelajaran, Membuat graph yang titiknya sudah diwarnai sesuai dengan simbol warna yang disepakati dibuat mulai hari Senin sampai dengan Sabtu, Membuat jadwal pelajaran sesuai dengan graph yang telah dibuat. Cara mengaplikasikan pewarnaan titik pada graph dalam pembuatan jadwal pelajaran adalah buatlah simbol warna dari masing-masing mata pelajaran, buatlah graph mulai dari hari Senin sampai dengan Sabtu sedemikian hingga setiap titik yang berhubungan langsung mendapatkan warna (sesuai dengan simbol warna yang telah dibuat dari masing-asing pelajaran) yang berbeda. Banyaknya titik pada graph disesuaikan dengan banyaknya mata pelajaran yang dipelajari mulai dari jam 07.00 -12.50 .
\end{abstract}

Kata Kunci: metode lattice, pembelajaran matematika.

\section{Pendahuluan}

Matematika mempunyai peranan yang sangat penting dalam kehidupan sehari-hari. Dalam catatan sejarah, matematika sangat dibutuhkan oleh manusia. Misalnya banyak persoalan kehidupan yang memerlukan kemampuan menghitung dan mengukur. Selain itu metematika juga berperan sebagai sarana untuk memecahkan masalah, baik pada matematika sendiri ataupun dalam bidang lain yang berkaitan dengan kehidupan nyata. Matematika juga mempunyai peranan penting dalam menunjang perkembangan ilmu pengetahuan dan teknologi (IPTEK), contohnya: aplikasi dalam bidang komunikasi, transportasi, engineering, komputer sains, dan bahkan sosial sains.

Matematika diskrit merupakan cabang ilmu dari matematika yang di dalamnya memuat tentang pengantar Teori Graph serta aplikasinya. Beberapa temuan penting dalam Teori Graph diperoleh pada abad kesembilan belas, tetapi baru pada sekitar 1920 minat akan Teori Graph berkembang. Akhirnya, teks pertama tentang Teori Graph muncul pada 1936. Tidak diragukan lagi, salah satu alasan bagi minat akan Teori Graph ini adalah penerapannya dalam berbagai bidang, termasuk ilmu komputer, kimia, 
riset operasi, teknik kelistrikan, dan ekonomi.

Aplikasi yang dapat diterapkan dalam kehidupan sehari-hari adalah pewarnaan pada graph. Pewarnaan graph terdiri dari tiga bagian yaitu pewarnaan titik, pewarnaan sisi, dan pewarnaan region. Pewarnaan-pewarnaan pada graph dapat diterapkan dalam berbagai bidang, salah satunya pewarnaan titik. Pewarnaan titik pada graph adalah pewarnaan semua titik di graph sedemikian hingga setiap dua titik yang berhubungan langsung mendapatkan warna yang berbeda (Budayasa, 2007:151). Pewarnaan titik pada graph dapat diterapkan dalam pembuatan jadwal pelajaran.

Membuat jadwal pelajaran merupakan salah satu tugas yang harus dikerjakan oleh wakil kepala sekolah bidang kurikulum setiap awal tahun pelajaran. Pembuatan jadwal akan menjadi masalah ketika jadwal yang disusun tidak dapat diselesaikan sebelum kegiatan efektif sekolah. Selama jadwal pelajaran belum selesai disusun maka kegiatan belajar mengajar di sekolah kurang efektif. Jadwal yang dibuat pada awal tahun pelajaran harus bersifat efektif agar tidak terjadi perubahan-perubahan jadwal yang memiliki banyak kendala seperti menyesuaikan hari dengan permintaan guru dan lain sebagainya.

Permasalahan belum selesainya jadwal pelajaran sebelum kegiatan belajar mengajar di sekolah dimulai pernah dialami oleh MTs Al-Hikmah Janti Jogoroto Jombang. Hal tersebut dikarenakan dalam mebuat jadwal masih menggunakan cara manual. MTs AlHikmah memiliki 6 kelas yaitu kelas 7 A dan 7 B, kelas 8 A dan 8 B, kelas 9 A dan 9 B. Banyaknya pengajar ada 20 orang. Terdapat 18 mata pelajaran yang diajarkan di MTs Al-Hikmah teridiri dari 8 mata pelajaran agama dan 10 mata pelajaran umum. Untuk mengatasi permasalahan dalam pembuatan jadwal, peneliti menawarkan suatu solusi dalam mengatasi permasalahan di atas yaitu menggunakan pewarnaan titik pada graph dalam membuat jadwal pelajaran. Tujuan dalam penelitian ini adalah untuk mendeskripsikan aplikasi pewarnaan titik pada graph dalam membuat jadwal pelajaran di MTs Al-Hikmah Janti Jogoroto Jombang.

Sebuah graph $G$ berisikan dua himpunan yaitu himpunan hingga tak kosong $\mathrm{V}(\mathrm{G})$ yang elemen-elemennya disebut titik dan himpunan (mungkin kosong) $\mathrm{E}(\mathrm{G})$ yang elemen-elemennya disebut sisi, sedemikian hingga setiap elemen e dalam $E(G)$ adalah sebuah pasangan tak berurutan dari titik-titik di $\mathrm{V}(\mathrm{G})$. V $(\mathrm{G})$ disebut himpunan titik dari $G$ dan $\mathrm{E}(\mathrm{G})$ disebut himpunan sisi dari G. Graph dapat dikelompokkan menjadi beberapa katagori (jenis) bergantung pada sudut pandang pengelompokannya. Pengelompokan graph dapat dipandang berdasarkan ada tidaknya sisi ganda (rangkap) atau gelung, berdasarkan jumlah simpul, atau berdasarkan orientasi arah pada sisi (Munir, 2003:293). Berdasarkan ada tidaknya gelung atau sisi ganda (rangkap) pada suatu graph, maka secara umum graph dapat digolongkan menjadi dua jenis yaitu graph sederhana dan graph tak sederhana.

Graph yang tidak mempunyai sisi ganda (rangkap) dan tidak memiliki gelung disebut graph sederhana. Yang termasuk graph sederhana yaitu graph lengkap, graph bipartisi. Graph yang mengandung sisi ganda atau gelung dinamakan graph taksederhana (unsimple-graph). Ada dua macam graph tak-sederhana, yaitu graph ganda (multigraph) dan graph semu (pseudograph).

Salah satu pokok bahasan dalam graph adalah pewarnaan graph. Ada dua jenis pewarnaan graph yaitu pewarnaan 
sisi pada graph dan pewarnaan titik pada graph. Pembahasan dalam penelitian ini, dibatasi hanya pada apllikasi pewarnaan titik pada graph. Sebuah pewarnaan titik pada graph $\mathrm{G}$ adalah pewarnaan semua titik $G$ sedemikian hingga setiap titik yang berhubungan langsung mendapat warna yang berbeda (Budayasa, 2007:151). Sebuah pewarnaan titik G dengan $\mathrm{k}$ buah warna disebut sebuah pewarnaan-titik-k pada graph G. Salah satu aplikasi pewarnaan titik pada graph adalah dapat digunakan dalam pembuatan jadwal pelajaran.

\section{Metode Penelitian}

Jenis penelitian ini berbentuk kualitatif dan prosesnya bersifat langsung serta terbuka dan dapat berubah, karena itu harus mengikuti perkembangan masalah di lapangan. Objek dalam penelitian ini adalah penjadwalan pelajaran di MTs Al-Hikmah Janti Jogoroto Jombang. Instrumen utama di penelitian ini adalah peneliti sendiri, dan instrumen pendukungnya adalah pedoman dokumentasi. Metode pengumpulan data nya menggunakan metode dokumentasi. Teknik analisis data yang digunakan pada penelitian ini adalah analisis pewarnaan titik pada graph. Analisis pewarnaan titik pada graph bermaksud untuk menentukan penjadwalan pelajaran secara efektif dan efisien.

\section{Hasil dan Pembahasan}

Berikut ini adalah klasifikasi mata pelajaran di MTs Al-Hikmah.

Tabel 1 : Klasifikasi Mata Pelajaran

\begin{tabular}{clcc}
\multicolumn{4}{c}{ Tabel 1 : Klasifikasi Mata Pelajaran } \\
\hline No. & $\begin{array}{c}\text { Mata } \\
\text { Pelajaran }\end{array}$ & $\begin{array}{c}\text { Kode Guru } \\
\text { Bidang } \\
\text { Studi }\end{array}$ & $\begin{array}{c}\text { Alokasi } \\
\text { Waktu }\end{array}$ \\
\hline 1 & Bhs. Arab & 13 & 3 JP \\
2 & IPA & 9 & 4 JP \\
3 & Matematika & 3 & 4 JP \\
4 & Penjaskes & 4 & 2 JP \\
5 & Qur'an Hadist & 5 & 2 JP \\
\hline
\end{tabular}

\begin{tabular}{clcc}
\hline 6 & BTQ & 5 & $2 \mathrm{JP}$ \\
7 & IPS & 6 & $4 \mathrm{JP}$ \\
8 & B. Inggris & 7 & $4 \mathrm{JP}$ \\
9 & SKI & 8 & $2 \mathrm{JP}$ \\
10 & Aqidah & 10 & $2 \mathrm{JP}$ \\
& Akhlak & 11 & $2 \mathrm{JP}$ \\
11 & PPKn & 19 & $4 \mathrm{JP}$ \\
12 & B. Indonesia & 14 & $1 \mathrm{JP}$ \\
13 & Aswaja & 15 & $2 \mathrm{JP}$ \\
14 & Nahwu & 16 & $2 \mathrm{JP}$ \\
15 & Seni Budaya & 18 & $2 \mathrm{JP}$ \\
16 & TIK & 19 & $1 \mathrm{JP}$ \\
17 & B. Daerah & 20 & $2 \mathrm{JP}$ \\
18 & Fiqih Jumlah & & $45 \mathrm{JP}$ \\
& &
\end{tabular}

Ket. JP = Jam Pelajaran

Pewarnaan yang digunakan dalam graph penjadwalan ini adalah pewarnaan titik. Pewarnaan titik yaitu pewarnaan semua titik $G$ sedemikian hingga setiap dua titik yang berhubungan langsung mendapat warna yang berbeda. Titik dalam graph penjadwalan ini merepresentasikan nama mata pelajaran dan kelas. Sisi dalam graph penjadwalan ini merepresentasikan jam pelajaran ke-n dengan $\mathrm{n}=1,2,3, \ldots$ Misal: $a_{7 a}$ artinya mata pelaiaran yang diajarkan dikelas 7 A. $\frac{1,2}{2}$ artinya jam pelajaran ke-1 dan 2. Berikut adalah simbol mata pelajaran yang digunakan dalam penelitian ini

Tabel 2 : Simbol Mata Pelajaran

\begin{tabular}{clc}
\hline No. & Mata Pelajaran & Simbol \\
\hline 1 & Bahasa Arab & $\mathrm{a}$ \\
2 & IPA & $\mathrm{b}$ \\
3 & Matematika & $\mathrm{c}$ \\
4 & Penjaskes & $\mathrm{d}$ \\
5 & Qur'an Hadist & $\mathrm{q}$ \\
6 & BTQ & $\mathrm{e}$ \\
7 & IPS & $\mathrm{s}$ \\
8 & Bahasa Inggris & $\mathrm{i}$ \\
9 & SKI & $\mathrm{k}$ \\
10 & Aqidah Akhlak & $\mathrm{h}$ \\
11 & PPKn & $\mathrm{p}$ \\
12 & Bahasa Indonesia & $\mathrm{g}$ \\
13 & Aswaja & $\mathrm{j}$ \\
14 & Nahwu & $\mathrm{n}$ \\
15 & Seni Budaya & $\mathrm{y}$ \\
16 & TIK & $\mathrm{t}$ \\
17 & Bahasa Daerah & $\mathrm{r}$ \\
\hline
\end{tabular}




18 Fiqih $\quad$ f

berikut peneliti sajikan gambar graph mulai hari Senin sampai dengan Sabtu dengan titik-titiknya telah diwarnai dengan simbol yang tertera pada Tabel 2

a. Hari Senin

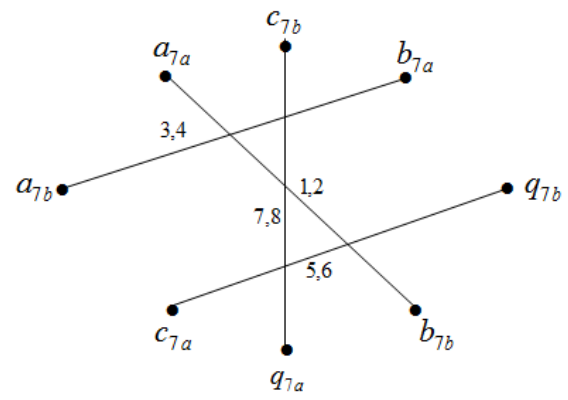

Gambar 1. Pewarnaan Titik pada Graph untuk Jadwal Hari Senin

Dari Gambar 1 dapat dijelaskan bahwa jam ke-1 dan 2 siswa kelas 7 A belajar Bahasa Arab dan siswa kelas 7 B belajar IPA. Jam ke-3 dan 4 siswa kelas 7 A belajar IPA dan siswa kelas 7 B belajar Bahasa Arab. Jam ke-5 dan 6 siswa kelas 7 A belajar Matematika dan siswa kelas 7 B belajar Quran Hadist. Jam ke-7 dan 8 siswa kelas 7 A belajar Quran Hadist dan siswa kelas 7 B belajar Matematika.

b. Hari Selasa

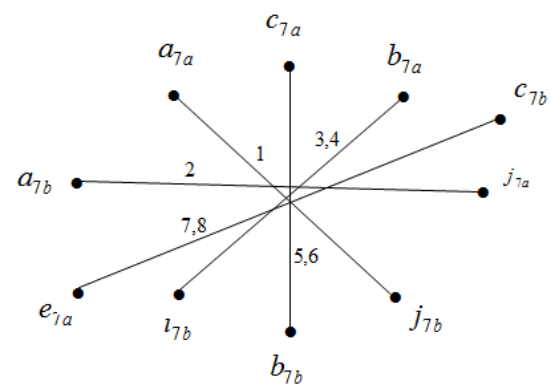

Gambar 2. Pewarnaan Titik pada Graph untuk Jadwal Hari Selasa

Dari Gambar 2 dapat dijelaskan bahwa jam ke-1 siswa kelas 7 A belajar Bahasa Arab. Jam ke-2 siswa kelas 7 B belajar Aswaja. Jam ke-3 dan 4 siswa kelas 7 A belajar IPA dan siswa kelas 7 B belajar Bahasa Inggris. Jam ke-5 dan 6 siswa kelas 7 A belajar Matematika dan siswa kelas 7 B belajar IPA. Jam ke-7 dan 8 siswa kelas 7 A belajar Baca Tulis Quran dan siswa kelas 7 B belajar Matematika

c. Hari Rabu

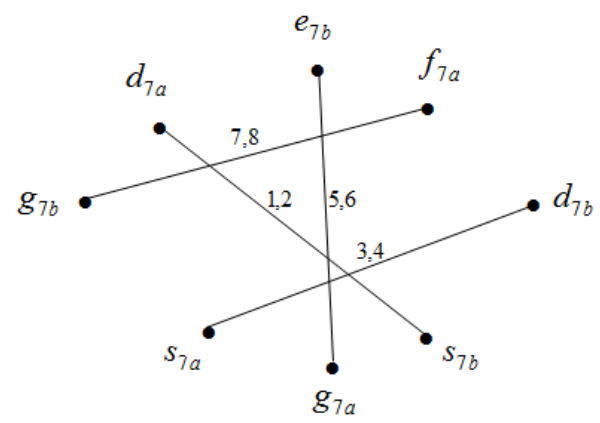

Gambar 3. Pewarnaan Titik pada Graph untuk Jadwal Hari Rabu

Dari Gambar 3 dapat dijelaskan bahwa jam ke-1 dan 2 siswa kelas 7 A belajar Penjaskes dan siswa kelas $7 \mathrm{~B}$ belajar IPS. Jam ke-3 dan 4 siswa kelas 7 A belajar IPS dan siswa kelas 7 B belajar Penjaskes. Jam ke-5 dan 6 siswa kelas 7 A belajar Bahasa Indonesia dan siswa kelas 7 B belajar Baca Tulis Quran. Jam ke-7 dan 8 siswa kelas 7 A belajar Fiqih dan siswa kelas 7 B belajar Bahasa Indonesia.

d. Hari Kamis

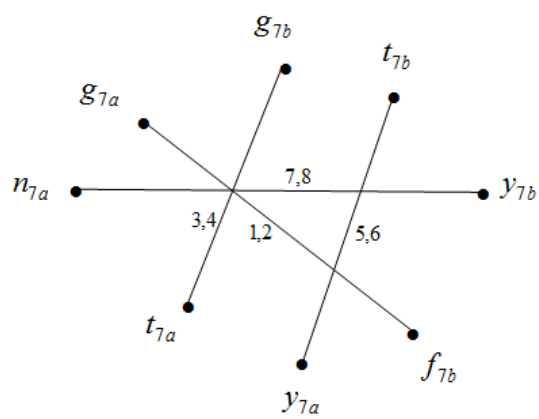

Gambar 4. Pewarnaan Titik pada Graph untuk Jadwal Hari Kamis

Dari Gambar 4 dapat dijelaskan bahwa jam ke-1 dan 2 siswa kelas 7 A belajar Bahasa Indonesia dan siswa kelas 
7 B belajar Fiqih. Jam ke-3 dan 4 siswa kelas 7 A belajar TIK dan siswa kelas 7 B belajar Bahasa Indonesia. Jam ke-5 dan 6 siswa kelas 7 A belajar Seni Budaya dan siswa kelas 7 B belajar TIK. Jam ke-7 dan 8 siswa kelas 7 A belajar Nahwu dan siswa kelas 7 B belajar Seni Budaya.

e. Hari Jum'at

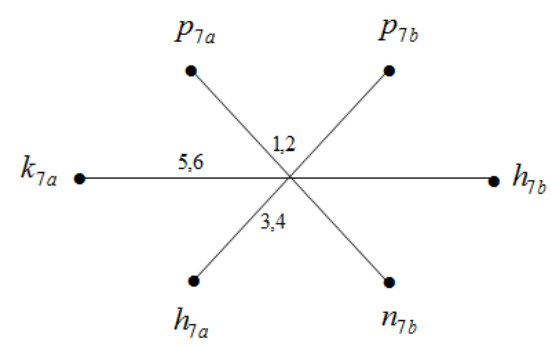

\section{Gambar 5. Pewarnaan Titik pada Graph} untuk Jadwal Hari Jum'at

Dari Gambar 5 dapat dijelaskan bahwa jam ke-1 dan 2 siswa kelas 7 A belajar PPKn dan siswa kelas 7 B belajar Nahwu. Jam ke-3 dan 4 siswa kelas 7 A belajar Aqidah Akhlak dan siswa kelas 7 B belajar PPKn. Jam ke-5 dan 6 siswa kelas 7 A belajar SKI dan siswa kelas 7 B belajar Aqidah Akhlak.

f. Hari Sabtu

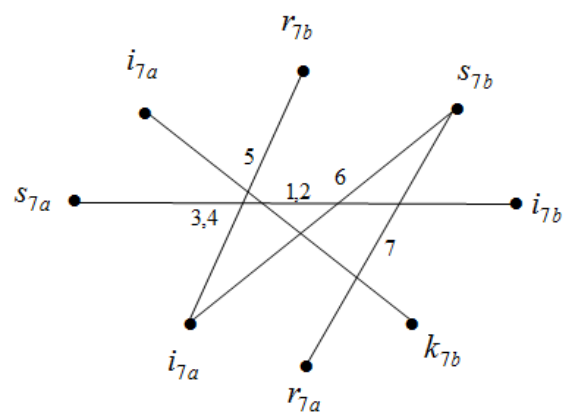

Gambar 6. Pewarnaan Titik pada Graph untuk Jadwal Hari Sabtu

Dari gambar 4.6 dapat dijelaskan bahwa jam ke-1 dan 2 siswa kelas 7 A belajar Bahasa Inggris dan siswa kelas 7 B belajar SKI. Jam ke-3 dan 4 siswa kelas 7 A belajar IPS dan siswa kelas 7 B belajar Bahasa Inggris. Jam ke-5 siswa kelas 7 A belajar Bahasa Inggris dan siswa kelas 7 B belajar Bahasa Daerah. Jam ke-6 siswa kelas 7 A belajar Bahasa Inggris dan siswa kelas 7 B belajar IPS. Jam ke-7 siswa kelas 7 A belajar Bahasa Daerah dan siswa kelas 7 B belajar IPS.

\section{Kesimpulan}

Pewarnaan titik pada graph dapat diaplikasikan dalam pembuatan jadwal pelajaran dengan cara:

a. buatlah simbol warna dari masingmasing mata pelajaran

b. buatlah graph mulai dari hari Senin sampai dengan Sabtu sedemikian hingga setiap titik yang berhubungan langsung mendapatkan warna (sesuai dengan simbol warna yang telah dibuat dari masing-asing pelajaran) yang berbeda. Banyaknya titik pada graph disesuaikan dengan banyaknya mata pelajaran yang dipelajari mulai dari jam 07.00 - 12.50 .

\section{Daftar Rujukan}

Arikunto, Suharsimi. 1997. Prosedur Penelitian Suatu Pendekatan Praktik. Jakarta: Rineka Cipta.

Arikunto, Suharsimi. 2002. Prosedur Penelitian Suatu Pendekatan Praktik. Jakarta: Rineka Cipta.

Badudu, J.S dan Sutan Mohammad Zain. 1994. Kamus Umum Bahasa Indonesia. Jakarta: Pustaka Sinar Harapan.

Budayasa, I Ketut. 1997. Teori Graph dan Aplikasinya. Surabaya:UNESA University Press.

Munir, R. 2003. Matematika Diskrit edisi Kedua. Bandung: Informatika.

Moleong, L J. 2011. Metodologi Penelitian Kualitatif edisi Revisi. Bandung: Remaja Rosdakary 